\title{
Preventing injuries in workers: the role of management practices in decreasing injuries reporting
}

\author{
Fariba Kiani ${ }^{1}$, Mohammad Reza Khodabakhsh, ${ }^{2,}$
}

\begin{abstract}
Background: Researchers have found that management safety practices may predict occupational injuries and psychological distresses in the workplace. The present study examined the perception of management safety practices related to injuries reporting and its dimensions among workers of Isfahan Steel Company (ESCO).

Methods: A self-administered anonymous survey was distributed to 189 workers. The survey included demographic factors, management safety perception, injuries reporting and its components (physical symptoms, psychological symptoms, and injuries). The data were analyzed by Multivariate and correlation techniques. Results: The results showed that: 1) there were significant correlations between management safety perception with injuries reporting and its two dimensions namely physical and psychological symptoms; 2) there was no significant relationship between management safety perception and injury; 3) in Multivariate analysis, management safety perception significantly predicted about $26 \%, 19 \%$, and $28 \%$ of the variances of variables of injuries reporting, physical symptoms, and psychological symptoms respectively $(P<0.01)$.

Conclusion: Improving employees' perception of management safety practices can be important to prevent the development of job injuries and to promote workers' safety and well-being.

Keywords: Management Safety Perception, Injuries Reporting, Physical Symptoms, Psychological Symptoms, Injuries, Workers

Copyright: @ 2014 by Kerman University of Medical Sciences

Citation: Kiani F, Khodabakhsh MR. Preventing injuries in workers: the role of management practices in decreasing injuries reporting. Int J Health Policy Manag 2014; 3: 171-177. doi: 10.15171/ijhpm.2014.83
\end{abstract}

Article History:

Received: 15 April 2014

Accepted: 6 September 2014

ePublished: 12 September 2014

\section{Key Messages}

Implications for policy makers

- Managers' actions and preferences about safety may help workers more accurately assess the risk of voicing concerns about safety issues.

- $\quad$ This feeling of social support may generate a sense of approval and the possibility of positive individual outcomes.

- Workers' perception of management support about safety is important in the etiology of physical and psychological symptoms.

- Establishing good relations among supervisors, managers, and subordinates is essential in organizations.

- Identifying important factors in the perception of support and the better design of human relations in the workplace can have an effect on the physical and psychological health of employees.

Implications for public

Occupational injuries are considered as one of the most important factors for disabled workers. Traditional methods to secure employees' safety have concentrated on the physical and biomechanical aspects of work by improving machines, equipment and task completion manners. However, it is believed that dimensions of psychosocial work environment such as perception of management support can be related to poor health. Employees with effective communication with mangers and their supervisors are better able to provide corrective feedback for unsafe behaviors (decreasing the probability of an injury) as well as rewarding feedback for safe behaviors and actions (increasing the likelihood of future behaviors being performed safely).

\section{Introduction}

The Steel industry has one of the highest rates/incidents of fatal and non-fatal injuries every year. As a high-risk industry, there is a need to investigate factors that affect the occurrence of these injuries to be able to protect workers (1). Management of an organization plays a critical role in supporting the professional standards, expectations, and requirements that are conducive to a more supportive occupational setting as well as having a pivotal role in the provision of workplace support (2). When organization agents such as supervisors and managers convey concern for worker safety by valuing suggestions for improving safety, workers develop such attitudes that their organization has a positive orientation towards their safety and well-being, which in turn increases the probability that employees will participate in safety related exchanges and in other safety-related actions $(3,4)$. This 
feeling of social support may generate a sense of approval and the possibility of positive individual outcomes (5).

Employees believe that the favorable or unfavorable orientation towards safety in the eye of the management of their organization is fostered by the assignment of humanlike characteristics to the organization (6). Levinson (7) noted that employees tend to view the organization as a living entity because it has responsibility for the actions of its agents; therefore, they develop global beliefs concerning the extent to which their organization values their contributions and cares about their safety and well-being.

Studies have shown that management openness is positively associated with general worker voice $(8,9)$. Clarke (10) showed that workers' intentions not to report safety incidents were related to their perception that management would take no notice. Also, Mullen (11) concluded that workers were more likely to invest time and effort into raising a safety issue when they thought managers were open to suggestions and opinions. Management openness to safety suggestions is only a moderate signal of organizational support for safety; managers and supervisors must also show their support for safety by acting on problems that are brought to their attention and preference (12). Researchers showed that the high levels of support in organizations may reduce occupational diseases and injuries among workers (13). Despite the importance of psychosocial dimensions of workplace such as perceived support in predicting occupational injuries, less research has been focused on this subject in Iran. Also, similar studies have mainly focused on particular industries as oil production, hospital personnel, petrochemical workers and car manufacturing workers (14-18), and no attempt has been made to describe these relationships among Steel industry workers.

\section{Methods}

\section{Participants}

This cross-sectional study was administrated between January and February 2012 in Esfahan Steel Company (ESCO). ESCO (Zob Ahan-e Esfahan) was launched in late 1960s, located near the cities of Fooladshahr and Zarrinshahr in Esfahan province, Iran. ESCO is the first and largest manufacturer of constructional Steel products in Iran $(\mathrm{No}=8300)(19)$. In this study, given the extent and distribution of the employees in the different parts of ESCO (Tohid Building, Navard part, blast furnace, steel making, coke, fire, railway, gas, oxygen plant, technical guidance etc.), stratified random sampling was used to select participants. The sample size was calculated using SPSS 15 (SPSS Inc., Chicago, IL, USA), following the procedure recommended by Molavi (20). Given $\alpha$ level 0.05 and a power of $90 \%$, the sample size required was estimated to be 180 subjects. Given the likelihood of failure to complete or return questionnaire, almost 200 employees were selected using stratified random sampling and questionnaires were distributed among them. The entry criterion for a person to this study was employment at different parts of the company and members at each part were then selected randomly. The exclusion criteria of the individuals were the delivery of incomplete questionnaire and lack of interest in participating in current research. Eleven (11) members were excluded from the main sample, 6 members due to the lack of interest in research topic, and 5 members due to incomplete questionnaires. 189 completed questionnaires were collected ( $95 \%$ rate of return). In order to control the confounding factors, questionnaires were completed by sample members in a quiet environment and away from the noise. Data gathered from the written responses showed a willingness by employees to participate in the research. Also, a covering letter explaining the purpose of the study, and ensuring confidential participation was taken into consideration as well. The anonymity of responses was guaranteed and managers and supervisors were made sure that their responses would not be shown to anybody and the results will be evaluated collectively, not individually. In addition; it is probable that there would be cultural barriers to injuries reporting in order to retain the apparent good safety record (21). To avoid this problem, the employees were assured that the proper reporting of injuries are important in the execution of this study, the responses are not seen by management and the purpose of this study is to improve their working conditions. Respondents were asked to return completed questionnaires inside sealed envelopes either to the person who had distributed them or directly to the research team.

\section{Measurements}

Validated instruments were used for data collection on management safety perception, injuries reporting and dimensions (physical symptoms, psychological symptoms and injury). First, all questionnaires were translated from English into Persian and were subsequently independently back-translated into English by a second translator. The few discrepancies between the original English and the backtranslated version resulted in adjustment in the Persian translation based on direct discussion between the translators. Second, the psychometric characteristics of instruments were examined. Linguistic validation was performed by three experts of psychology department and five experts of safety and health departments. Thus, the questionnaires were piloted and finalized with an advisory group of workers to ensure that the scale items were comprehensible and appropriate to the context. Moreover, conceptual analysis confirmed the content validity of all instruments. The questionnaires were distributed to workers with the help of union steward. Participants were assured of confidentiality and informed consent was obtained from each individual. The following questionnaires were used:

Demographic factors. Five demographic factors, namely age, gender, marital status, education, and years of working experience, were included. Marital status was classified as married or not married (including divorced and widowed). Management safety perception. Management safety perception with 7 items of Hayes, Perander, Smecko and Trask (22) were measured. Questions in the questionnaire refer to perceptions about management attitudes and values of an organization related to safety issues. Respondents indicated the extent of agreement with each statement on a 5-point Likert-type scale ( $1=$ strongly disagree; $5=$ strongly agree). 
The scores of participants were obtained by adding their responses to a 7-item questionnaire. Munteanu (23), in her study, calculated the internal reliability of this scale using Cronbach's alpha (0.81). Evidence for the reliability of this scale, as administered to Iranian relevant populations, in this research, by alpha coefficient is 0.78 and by Split-half is 0.77 . The validity coefficients of questions are between 0.22 and 0.76 . All validity coefficients are significant at $P<0.01$.

Injuries reporting scale. This questionnaire is a tool for collecting data on reporting injuries scale of Barling, Loughlin, Kelloway (24) and it includes three components namely physical symptoms, psychological symptoms and injuries.

Physical symptoms scale. This scale is a 20 -item questionnaire of Barling et al. (24). It is constructed based on the frequency of physical symptoms that employees have experienced

Table 1. Questionnaire adapted from Baling et al. (24)

\begin{tabular}{|c|c|}
\hline \multicolumn{2}{|r|}{$\begin{array}{l}\text { Injuries Reporting Scale [with a 5-point Likert style from } 1 \text { (never) to } 5 \\
\text { (more than } 5 \text { times)] }\end{array}$} \\
\hline \multicolumn{2}{|r|}{$\begin{array}{l}\text { In the last month, how frequently did you experience these on the } \\
\text { job? }\end{array}$} \\
\hline \multicolumn{2}{|r|}{ Physical Symptoms } \\
\hline 1. & Headache or dizziness \\
\hline 2. & Persistent fatigue \\
\hline 3. & Skin rash/burn \\
\hline 4. & Strain or sprain (e.g. back pain) \\
\hline 5. & Cut or puncture (open wound) \\
\hline 6. & Temporary Loss of hearing \\
\hline 7. & Eye injury \\
\hline 8. & Electrical shock \\
\hline 9. & Respiratory injuries (e.g. difficulty breathing) \\
\hline 10 & Dislocated/fracture bone \\
\hline 11 & Hernia \\
\hline \multicolumn{2}{|c|}{ Psychological Symptoms } \\
\hline 1. & Loss of much sleep due to work related worries \\
\hline 2. & Unable to concentrate on work-related tasks \\
\hline 3. & Felt constantly under strain \\
\hline 4. & Felt incapable of making decisions \\
\hline 5. & Lost confidence in myself \\
\hline 6. & Unable to enjoy my normal day-to-day activities \\
\hline \multicolumn{2}{|r|}{ Injury } \\
\hline 1. & Was exposed to chemicals such as gases and fumes \\
\hline 7. & Over exerted myself while handing, lifting or carrying \\
\hline 2. & Slipped, tripped or fell \\
\hline 3. & Fell from height \\
\hline 4. & Was struck by a moving vehicle \\
\hline 5. & Was struck by flying/falling object(s) \\
\hline 6. & Struck against something fixed or stationary \\
\hline 7. & Was trapped by something collapsing, caving in or overturning \\
\hline & Contacted moving machinery \\
\hline \multicolumn{2}{|c|}{ 9. Other (Please specify) } \\
\hline \multicolumn{2}{|r|}{$\begin{array}{l}\text { Management safety perception [with a 5-point Likert-type scale from } \\
1 \text { (strongly disagree) to } 5 \text { (strongly agree)] }\end{array}$} \\
\hline 1. & Our management provides enough safety training programs \\
\hline 2. & Our management conducts frequent safety inspections \\
\hline 3. & Our management investigates safety problems quickly \\
\hline 4. & Our management rewards safe workers \\
\hline 5. & Our management provides safe equipment \\
\hline 6. & Our management provides safe working conditions \\
\hline 7. & Our management keeps workers informed of hazards \\
\hline
\end{tabular}

them in their jobs during the past month. Scoring is based on a Likert style of five degrees from 1 (never) to 5 (more than 5 times). Sum of the scores given to items is reported as the total score of physical symptoms for a worker. Prior studies surveying many industries and organizations provide evidence for high internal reliability and criterion validity of the scale (23). Internal consistency (Cronbach's alpha) in this study in Iran was 0.81 , which is good for this scale.

Psychological symptoms scale. This scale is a tool with 7 items of Barling et al. (24). It is based on the frequency of psychological symptoms that employees have experienced them in their jobs during the past month. Scoring is based on a Likert style of five degrees from 1 (never) to 5 (more than 5 times). Psychological distress scores are from 0 to 28. The high scores indicate more psychological distress experienced by each individual. Mantineau (23) reported the internal validity of this scale using Cronbach's alpha (0.83). Also, she showed that this scale had good criterion validity. Internal consistency (Cronbach's alpha) in this study in Iran was 0.79, which is good for this scale.

Injury. This scale is a tool with 10 items of Barling et al. (24). It is based on the frequency of injuries that employees have experienced them in their jobs during the past month. Scoring is based on a Likert style of five degrees from 1 (never) to 5 (more than 5 times). Mantineau (23) reported the internal reliability of this scale using Cronbach's alpha 0.83 . Also, she showed that this scale had good criterion validity. Internal

Table 2. Demographic characteristics of the sample members $(\mathrm{N}=189)$

\begin{tabular}{|c|c|c|}
\hline & Number & $\%$ \\
\hline \multicolumn{3}{|l|}{ Age } \\
\hline 18 to 29 years & 68 & 36 \\
\hline 30 to 41 years & 68 & 36 \\
\hline 42 to 53 years & 53 & 28 \\
\hline \multicolumn{3}{|l|}{ Gender } \\
\hline Male & 170 & 90 \\
\hline Female & 19 & 10 \\
\hline \multicolumn{3}{|l|}{ Marital status } \\
\hline Married & 113 & 60 \\
\hline Single & 76 & 40 \\
\hline \multicolumn{3}{|l|}{ Education } \\
\hline Master degree & 22 & 12 \\
\hline University graduates & 45 & 24 \\
\hline High school graduates & 113 & 60 \\
\hline Primary school graduates and lower & 9 & 4 \\
\hline \multicolumn{3}{|l|}{ Work experience } \\
\hline 5 years and lower & 68 & 36 \\
\hline 6 to 15 years & 45 & 24 \\
\hline 16 to 25 years & 45 & 24 \\
\hline 26 years and higher & 31 & 16 \\
\hline \multicolumn{3}{|l|}{ Shift status } \\
\hline Shift & 120 & 64 \\
\hline Not shift & 69 & 36 \\
\hline
\end{tabular}


consistency (Cronbach's alpha) in this study in Iran was 0.79, which is good for this scale.

The score of injuries reporting is obtained from the sum of these three dimensions. Munteanu (23), in her study, calculated the internal reliability of this scale using Cronbach's alpha (0.80). Evidence of reliability of this scale, as administered to Iranian relevant populations, in this research, by Alpha coefficient is 0.83 and by Split-half is 0.81 . The validity coefficients of questions are between 0.21 and 0.83 . All validity coefficients are significant at $P<0.01$.

The questionnaires of management safety perception, injuries reporting and its dimensions are represented in Table 1.

\section{Statistical analyses}

In order to calculate the internal correlation coefficients and the amount of shared variance between management safety perception, injuries reporting and dimensions (physical symptoms, psychological symptoms, and injury), Pearson correlation technique, Multivariate and Univariate analysis were performed. Multivariate statistics is a form of statistics encompassing the simultaneous observation and analysis of more than one outcome variable at a time. In design and analysis, all analyses were conducted using SPSS 15 (SPSS Inc., Chicago, IL, USA) and the level of significance was set at alpha $=0.05$.
Results

Part I: Demographic characteristics of participants

Almost the majority of participants were male because they were the main occupational groups at production line in this study. Ages ranged from 18 to 53; the median age of the participants was 32 years. Frequency and frequency percentages of demographic variables distribution are presented in Table 2.

\section{Part II: Descriptive statistics}

Mean, standard deviation, and internal correlations of variables are presented in Table 3.

As can be seen, the relationships between management safety perception with injuries reporting and its two dimensions namely physical and psychological symptoms were significant $(P<0.01)$. There was not a significant relationship between management safety perception and injury $(P>0.05)$.

\section{Part III: Multivariate analysis}

We examined the data on management safety perception, injuries reporting and its dimensions, and found that there was not only homogeneity of variances $(\mathrm{F}=0.32, P>0.05)$, but also, the data were normally distributed. To assess the predictive power of injuries reporting and its dimensions by management safety perception, canonical correlation method

Table 3. Mean, standard deviation variable, and internal correlations under study

\begin{tabular}{|c|c|c|c|c|c|c|c|c|}
\hline \multirow{2}{*}{ Variable } & \multirow{2}{*}{ Number } & \multirow{2}{*}{ Mean } & \multirow{2}{*}{ SD } & \multicolumn{5}{|c|}{ Correlations } \\
\hline & & & & 1 & 2 & 3 & 4 & 5 \\
\hline Injuries reporting & 189 & 37.42 & 8.05 & 1 & & & & \\
\hline Management safety perception & 189 & 27.79 & 4.41 & $-0.52 *$ & 1 & & & \\
\hline Physical symptoms & 189 & 14.86 & 3.67 & $0.73^{*}$ & $-0.44^{*}$ & 1 & & \\
\hline Psychological symptoms & 189 & 9.88 & 3.44 & $0.76^{*}$ & $-0.53^{*}$ & $0.63^{*}$ & 1 & \\
\hline Injury & 189 & 12.67 & 8.04 & $0.71 *$ & -0.26 & $0.48 *$ & $0.39 *$ & 1 \\
\hline
\end{tabular}

Table 4. Multivariate Analysis of Variance (MANVOA) of the predictor variable of management safety perception based on the criterion variables of injuries reporting and its dimensions

\begin{tabular}{lcccccccc}
\hline Effect & Value & F & df & Error df & $\boldsymbol{P}$ & Partial eta-squared & No cent. parameter & Observed power \\
\hline Pillai's trace & 0.30 & 6.58 & 3 & 185 & 0.00 & 0.30 & 19.76 \\
Wilk's lambda & 0.69 & 6.58 & 3 & 185 & 0.00 & 0.30 & 19.76 \\
Hotelling's trace & 0.43 & 6.58 & 3 & 185 & 0.00 & 0.30 & 19.76 \\
Roy's largest root & 0.43 & 6.58 & 3 & 185 & 0.00 & 0.30 & 0.96 \\
\hline
\end{tabular}

Table 5. Univariate analysis of variance on scores of injuries reporting and its dimensions according to predictive variable of management safety perception

\begin{tabular}{lccccc}
\hline Dependent variable & Mean square & df & F & Partial eta-squared & Observed power \\
\hline Injuries reporting & 842.91 & 1 & 17.35 & 0.00 & 0.26 \\
Physical symptoms & 131.16 & 1 & 11.90 & 0.00 & 0.19 \\
Psychological symptoms & 165.48 & 1 & 19.04 & 0.00 & 0.28 \\
Injury & 22.24 & 1 & 3.58 & 0.06 & 0.99 \\
\hline
\end{tabular}


was used. This method is performed with Multivariate analysis. The results are presented in Table 4 .

As shown in Table 4, management safety perception predicted almost $30 \%$ of variance of injuries reporting and its dimensions $(P<0.01)$. Univariate analysis of variance on the criterion variables considering predictor variable of management safety perception are presented in Table 5. As can be seen, management safety perception variable significantly predicted about $26 \%, 19 \%$, and $28 \%$ of the variance of variables of injuries reporting, physical symptoms, and psychological symptoms respectively $(P<0.01)$. Also, management safety perception predicted about $7 \%$ of the variance of injury variable but this prediction was not statistically significant $(P>0.05)$.

\section{Discussion}

The results of the present study indicated that management safety perception significantly predicted the variables of injuries reporting, physical symptoms, and psychological symptoms. This is consistent with the findings of the previous studies (25-27) and can be interpreted on the basis of the following possibilities:

First, the importance of management safety perception seems reasonable. Management safety perception is essential in order to motivate employees to excel and provide support in workplace. Previous research showed that the high levels of social support were related to decreased work stress and a greater appreciation of the work (28). The mechanism behind this relationship is that when workers perceive that they have a high level of social support to draw on, they are less likely to estimate their environment as stressful and can manage various work demands, therefore they are less susceptible to the psychological and physical symptoms. Management support may prepare employees to adjust better to work demands. The perception of support is a resource that reduces the perception of stressors in the workplace. Perceived support of management provides a psychological and physical resource that influences the psychological state of employees. Previous research indicated that the level of burnout can be reduced, if workers be able to negotiate about work problems with their managers (29).

Second, employees with management safety perception realize that their health and safety for management is more important than the mere production; so they do not spend all their time to do jobs faster but do their work with more patience. On the other side, employees with the perception of work pressure have more job stress and do their work rapidly; therefore, at the time of working with organization's machinery and perhaps even at the time of commuting to workplace they involve in more injuries. The perception of employees about the management philosophy of production or safety, after the organization's policy towards safety, was the second important factor in predicting safety performance (30). When employees perceive that managers are supportive, concerned, and interested in their safety and well-being, they are more likely to realize that their organizations value their safety as well (31).

Third, the theory of Demand-Control (DC), describes work stress as it develops from the structural or organizational aspects of the work environment and not the individual characteristics (32). A part of this theory is the interaction between the job demands which is put on the employees and the management to coordinate those demands (33). Employees involved in positions with low control, high demands, and low support, are in a higher danger of physical and psychological harm from work stress (34). Mcclenahan et al. (35) concluded that high demands and low control and low support accounted for $26 \%, 6 \%$, and $8 \%$ of the variance in job satisfaction, psychological distress and burnout, respectively. Lack of support and poor communication may act as stressors, therefore leading to the perception of work stress (36). Providing essential information and skills about mental health, including occupational stressors, have an impact on the mental health of employees, at least in the short term (37). By providing information to subordinates or conveying attitudes or opinions about safety to them, managers can act as a driving force affecting workplace safety (3). In order to minimize the occurrence of physical and psychological symptoms, it is important to provide support for employees (38). Most organizations spend all their time to design interventions to reduce stress. Although employees will learn how to deal with stressors, but when they enter the workplace, due to the poor relations with supervisors and managers, they involve in a paradoxical situation that makes the transfer of learning from training interventions be weak, and again they fall in the same destructive cycle of conflicts. Studies have shown that managers' support and the quality of communication between the managers and employees have a significant impact on the transfer of learning from training interventions (39).

Regarding the week relationship between management safety perception and injury it can be said that in order to establish this relationship there should be other conditions such as high-risk environments, unsafe equipment and machines, coworkers support, risk taking, etc. Parker et al. (40) stated that focusing on managers' behaviors alone is scant for developing a more proactive workforce.

Therefore, in organizations supervisors and managers should learn how to establish good relations with subordinates. It is worth noting that the current observation could also suggest that the degree of the employees' perceptions on organizational safety might have resulted in their perceptions on management practices about safety issues. From the current study findings, it seems that management safety perception could be considered as diagnostic tools for assessing the perceptions of employees' safety and organizational support, and for predicting occupational diseases and injury frequencies. A significant practical implication in the workplace would be that interventions aimed at demonstrating managers' support and concern for workers' well-being should be intensified in workplaces. The literature on management safety perception is satiated with such organizational structures: increasing job satisfaction (25), conducting fairness perception measures $(25,41,42)$, providing support, and showing commitment to workers beyond what is formally stated in the conventional agreement $(27,41)$. Efforts to influence the values and 
attitudes of workers about safety and thus motivating them to engage in safe work activities may fail if the environment is not supportive. The observed higher injuries for employees' with lower supportive perceptions could be remedied if management of an organization openly and convincingly demonstrates concern for workers' well-being and safety. This can be achieved by providing the right work equipment, job enrichment processes, skill-training opportunities, and visiting workplaces to alert employees of dangerous work actions, and explicitly expressing concern for their safety and well-being. Bonus and incentive schemes could be instituted as actions to motivate occupational safety. Employees who respond positively could be obviously rewarded and trained as frontline workers and supervisors to serve as models to motivate other employees $(43,44)$.

\section{Conclusion}

In summary, our findings suggest that the management safety perception predicted injuries reporting and its dimensions (physical symptoms, psychological symptoms). Also, we can say that in situations with low support of managers, workers suffer from physical and mental illnesses but because the management safety perception leads to injury, there should be other conditions such as risk conditions, low job control, high job pressure, and work overload, etc. In other words, management safety perception for the injuries is a necessary condition but not enough. Therefore, organizational support should be maximized to optimize the physical and mental health of workers.

This study was limited by the work environment. Future studies would be useful if they are done in other industries and countries. Consequently, the findings of the study should be interpreted with caution. Further, the cross-sectional design of the study and participants (i.e. a group of employees) exert some limitations on the generalization of the findings. Finally, the problems and limitations on the use of selfreporting instruments should not be overlooked. However, limitations are usually accepted because self report surveys are considered as the most practical way to collect data and to reflect individual attitudes and behaviors $(45,46)$. In addition, the instruments of this study were selected with respect to the contents of their items in coordination to the Steel industry and may be less applicable in other industries.

\section{Acknowledgements}

The authors would like to acknowledge the generosity of employees who agreed to participate in this research. This study was financially supported by the research committee of psychology department and educational sciences of Esfahan University and Esfahan Steel Company (ESCO).

\section{Ethical issues}

This study was approved by the constituted ethics committees where the work was done. Also, no ethical hazard is known to authors of the research. Informed consent was obtained from each participant.

Competing interests

The authors declare that they have no competing interests.
Authors' contributions

FK wrote the study design; data were collected and analyzed by FK and MRK. Final manuscript was prepared by FK and MRK. All authors commented on the successive versions of the manuscript.

\section{Authors' affiliations}

${ }^{1}$ Young Researchers and Elite Club, Shahrekord Branch, Islamic Azad University, Shahrekord, Iran. ${ }^{2}$ Young Researchers and Elite Club, Mashhad Branch, Islamic Azad University, Mashhad, Iran.

\section{References}

1. Kiani F, Samavatyan H, Pourabdian S, Jafari E. Predictive power of injuries reporting and its dimensions by job stress among workers' Isfahan Steel Company. Iran J Public Health 2011; 40: 105-12.

2. Mor Barak ME, Nissly JA, Lane CJ. Why do they leave? Modeling child welfare workers' turnover intentions. Children and Youth Services Review 2006; 28: 548-77. doi: 10.1016/j. childyouth.2005.06.003

3. Hofmann DA, Morgeson FP. Safety-related behavior as a social exchange: The role of perceived organizational support and leader-member exchange. J Appl Psychol 1999; 84: 286-96. doi: $10.1037 / / 0021-9010.84 .2 .286$

4. Michael JH, Evans DD, Jansen KJ, Haight J M. Management commitment to safety as organizational support: Relationships with non-safety outcomes in wood manufacturing employees. J Safety Res 2005; 36: 171-9. doi: 10.1016/j.jsr.2005.03.002

5. Nembhard IM, Edmondson AC. Making it safe: The effects of leader inclusiveness and professional status on psychological safety and improvement efforts in health care teams. J Organ Behav 2006; 27: 941-66. doi: 10.1002/job.413

6. Eisenberger R, Huntington R, Hutchison S, Sowa D. Perceived organizational support. J Appl Psychol 1986; 71: 500-7. doi: 10.1037//0021-9010.71.3.500

7. Levinson $\mathrm{H}$. Reciprocation: The relationship between man and organization. Adm Sci Q 1965; 9: 370-90. doi: 10.2307/2391032

8. Detert JR, Burris ER. Leadership behavior and employee voice. Acad Manage J 2007; 50: 869-84. doi: 10.5465/ amj.2007.26279183

9. Saunders DM, Sheppard BH, Knight V, Roth J. Employee voice to supervisors. Employee Responsibilities and Rights Journal 1992; 5: 241-59. doi: 10.1007/bf01385051

10. Clarke S. Organizational factors affecting the incident reporting of train drivers. Work \& Stress 1998; 12: 6-16. doi: 10.1080/02678379808256845

11. Mullen J. Testing a model of employee willingness to raise safety issues. Canadian Journal of Behavioral Science 2005; 37: 273 82. doi: $10.1037 / \mathrm{h} 0087262$

12. Harlos KP. When organizational voice systems fail. J App/ Behav Sci 2001; 37: 324-42. doi: 10.1177/0021886301373005

13. Dickinson NS, Perry RE. Factors influencing the retention of specially educated public child welfare workers. $J$ Health Soc Policy 2002; 15: 89-103. doi: 10.1300/j045v15n03_07

14. Chen W, Huang Z, Yu D, Lin Y, Ling Z, Tang J. An exploratory study on occupational stress and work-related unintentional injury in off-shore oil production. Zhonghua Liu Xing Bing Xue Za Zhi 2002; 3: 441-5.

15. Salminen S, Kivimäki M, Elovainio M, Vahtera J. Stress factors predicting injuries of hospital personnel. Am J Ind Med 2003; 44: 32-8. doi: 10.1002/ajim.10235

16. Li CY, Chen $\mathrm{KR}, \mathrm{Wu} \mathrm{CH}$. Job stress and dissatisfaction in association with non-fatal injuries on the job in a cross-sectional sample of petrochemical workers. Occup Med (Lond) 2001; 51 : 50-5.

17. Murata K, Kawakami N, Amari N. Does job stress affect injury 
due to labor accident in Japanese male and female bluecollar workers? Ind Health 2000; 38: 246-51. doi: 10.2486/ indhealth.38.246

18. Soori H, Rahimi M, Moheseni H. Occupational stress and workrelated unintentional injuries among Iranian car manufacturing workers. East Mediterr Health J 2008; 14: 697-703.

19. Profile of Esfahan Steel Company [internet]. 2014. Available from: http://www.esfahansteel.com/steel_en.php

20. Molavi H. SPSS 10-13-14 applied guidance in behavioral sciences. Isfahan: Poyesh Andishe Publication; 2007.

21. Waring JJ. Beyond blame: cultural barriers to medical incident reporting. Soc Sci Med 2005; 60: 1927-35. doi: 10.1016/j. socscimed.2004.08.055

22. Hayes BE, Perander J, Smecko T, Trask J. Measuring perceptions of workplace safety: development and validation of the work safety scale. J Safety Res 1998; 29: 145-61. doi: 10.1016/s0022-4375(98)00011-5

23. Munteanu MR. Safety attitudes in the Ontario construction. Canada: University of Toronto; 2005.

24. Barling J, Loughlin C, Kelloway EK. Development and test of a model linking safety-specific transformational leadership and occupational safety. J appl Psychol 2002; 78: 488-96. doi: 10.1037//0021-9010.87.3.488

25. Williams L, Anderson S. Job satisfaction and organizational commitment as predictors of organizational citizenship and in-role behaviours. J Manag 1991; 17: 601-18. doi: 10.1177/014920639101700305

26. Iverson RD, Erwin PJ. Predicting occupational injury: the role of affectivity. J Occup Organ Psych 1997; 70: 113-28. doi: 10.1111/ j.2044-8325.1997.tb00637.x

27. O'Toole M. Successful safety committees: participation not legislation. J Saf Res 1999; 30: 39-65. doi: 10.1016/s00224375(98)00061-9

28. AbuAIRub RF. Job stress, job performance, and social support among hospital nurses. Journal of Nursing Scholarship 2004; 36: 73-8. doi: 10.1111/j.1547-5069.2004.04016.x

29. Ito $H$, Kurita $H$, Shiiya J. Burnout among direct-care staff members of facilities for persons with mental retardation in Japan. Ment Retard 1999; 37: 477-81.

30. Diaz RT, Cabrera DD. Safety climate and attitude as evaluation measures of organizational safety. Accid Anal Prev 1997; 29: 643-50. doi: 10.1016/s0001-4575(97)00015-8

31. Gyekye SA, Salminen S. Workplace Safety Perceptions and Perceived Organizational Support: Do Supportive Perceptions Influence Safety Perceptions? Int J Occup Saf Ergon 2007; 13: 189-200.

32. Karasek RA, Theorell T. Healthy work: Stress, productivity and the reconstruction of working life. New York: Basic Books; 1990.
33. Vegchel NV, Jonge JD, Landsbergis PA. Occupational stress in interaction: The interplay between job demands and job resources. J Organ Behav 2005; 26: 535-60. doi: 10.1002/ job. 327

34. Dollard MF, Winefield HR, Winefield AH, Jonge JD. Psychosocial job strain and productivity in human service workers: A test of the demand-control-support model. J Occup Organ Psychol 2000; 73: 501-10. doi: 10.1348/096317900167182

35. Mcclenahan A, Giles ML, Mallett GJ. The importance of context specificity in work stress research: a test of the Demand-ControlSupport model in Academics. Work \& stress 2007; 21: 85-95. doi: 10.1080/02678370701264552

36. Steinhardt MA, Dolbier CL, McCalister KT. The relationship between hardiness, supervisor support, group cohesion, and job stress as predictors of job satisfaction. Am J Health Promot 2003; 17: 382-91. doi: 10.4278/0890-1171-17.6.382

37. Naghami M, Tsutsumi A, Tsuchiya M, Morimoto K. Job control and coworker support improves employee job performance. Ind Health 2010; 48: 845-51. doi: 10.2486/indhealth.ms1162

38. Babin BJ, Boles JS. The effects of perceived co-worker involvement and supervisor support on service provider role stress, performance and job satisfaction. Journal of Retailing 1996; 72: 57-75. doi: 10.1016/s0022-4359(96)90005-6

39. Ismail A, Hasan ABM, Sulaiman AZ. Supervisor's Role as an Antecedent of Training Transfer and Motivation to Learn in Training Programs. Economica 2010; 7: 12-24.

40. Parker SK, Williams HM, Turner N. Modeling the antecedents of proactive work behavior at work. J Appl Psychol 2006; 91: 636-52. doi: 10.1037/0021-9010.91.3.636

41. Simons T, Robertson Q. Why managersshould care about fairness: the effect of aggregate justice perception on organizational outcomes. J Appl Psychol 2003; 83: 432-43.

42. Shore L, Shore T. Perceived Organizational Support and organizational justice. In: Cropanzano R, Kacmar K, editors. Organizational politics, justice, and support. Westport, CT: Quorum Books; 1995. p. 149-64.

43. Bandura A. Principles of behavior modification. New York: Holt, Rinehart \& Winston; 1969.

44. Zohar D, Luria, G. The use of supervisory practices as leverage to improve safety behaviour: a cross-level intervention model. $J$ Saf Res 2003; 34: 567-77. doi: 10.1016/j.jsr.2003.05.006

45. Griffin MA, Neal N. Perceptions of safety at work: A framework for linking safety climate to safety performance, knowledge, and motivation. J Occup Health Psychol 2000; 5: 347-58. doi: 10.1037//1076-8998.5.3.347

46. Neal A, Griffin MA, Hart PM. The impact of organizational climate on safety climate and individual behaviour. Saf Sci 2000; 34: 99109. doi: 10.1016/s0925-7535(00)00008-4 